\title{
Automatic calculation method of load resonant frequency of photovoltaic power supply
}

\author{
Xinying Zhao \\ Department of Electronic Engineering, Zhengzhou Railway Vocational and Technical College, \\ Zhengzhou, 450000 \\ China \\ Kun Luo* \\ School of International Education, Zhengzhou Railway Vocational and Technical College, \\ Zhengzhou, 450000 \\ China
}

Received: March 14, 2021. Revised: July 18, 2021. Accepted: August 9, 2021. Published: August 11, 2021

\begin{abstract}
The resonance phenomenon of photovoltaic power supply load makes the output voltage of grid-connected photovoltaic power supply system difficult to keep stable, which brings trouble to power supply. Therefore, it is necessary to study the automatic calculation method of load resonance frequency of photovoltaic power supply, so as to detect the load resonance frequency of photovoltaic power supply in real time, thereby ensuring the normal operation of photovoltaic power supply system. The load resonance frequency of photovoltaic power supply is divided into steady-state load resonance frequency and dynamic load resonance frequency. The mathematical model of load resonant circuit of photovoltaic power supply is established by calculating algorithm of load resonant frequency of photovoltaic power supply in steady state, and load resonant frequency of photovoltaic power supply in steady state is calculated. The resonance detection algorithm based on wavelet transform and Hilbert-Huang transform is used to analyze and calculate the load resonance frequency after detecting the resonance signal of photovoltaic power system. The experimental results show that the resonant frequency of photovoltaic power supply load calculated by this method is not much different from the actual resonant frequency of photovoltaic power supply load, and the error range is between-0.30\% and $0.49 \%$. Therefore, this method can keep the load resonance frequency of the photovoltaic power supply the same as the RF transmission resonance frequency, and can ensure the normal operation of the photovoltaic power supply.
\end{abstract}

Keywords-Automatic Calculation, Load Resonance Frequency, Photovoltaic Power Supply, Wavelet Transform.

\section{INTRODUCTION}

With the progress of society and the development of science and technology, the problems of environmental pollution and energy shortage have become more and more serious. At present, China's focus on energy research is toward renewable energy sources such as photovoltaic power, because the grid-connected photovoltaic power will be widely applied in the future development of electricity. However, the continuous increase of the photovoltaic penetration rate will cause abnormality of the photovoltaic power supply, and affect the safety of the distribution network and reduce the quality of electrical energy [1].

In the past few years, photovoltaic power supply has been widely studied. Considering its stability, the equivalent circuit model is composed of diode, series resistance, parallel resistance and photocurrent generator. The optimal power conversion efficiency of the battery is determined to be 5\% [2]. In order to improve the performance of photovoltaic power supply, the parameters of power supply materials are calculated by using density functional theory, and the pressure-temperature correlations of thermal expansion coefficient, bulk modulus, specific heat, Debye temperature and entropy Greennathan parameters are described, and the buffer layer has the highest efficiency, reaching $22.9 \%$ [3]. In the photovoltaic control system, the application of the maximum power point tracking method is the key factor to make the photovoltaic module run efficiently under shading conditions. The parameters of photovoltaic control are extracted by semantic web rule language, and an efficient photovoltaic system is realized [4].

In the grid-connected photovoltaic power supply system, due to the configuration of many electric power devices, the photovoltaic power supply has certain fluctuations, which 
causes the load of the photovoltaic power supply in the grid-connected photovoltaic power supply system to contain more complex resonances. When the resonance frequency of a photovoltaic power supply is equal to the frequency of a certain harmonic frequency, resonance will occur in the photovoltaic power supply load in the grid-connected photovoltaic power system, which can cause the fluctuation of voltage and current in the grid-connected photovoltaic power supply system, make the system unable to operate normally, cause tripping, seriously affect the operation of the grid-connected photovoltaic power supply system, and reduce the reliability of the power supply system [5]. The effective method of automatic calculation of load resonance frequency of photovoltaic power supply can detect the load resonance frequency and amplitude of photovoltaic power supply in the steady or dynamic state, reduce the automatic tripping in the grid-connected photovoltaic power supply system, and ensure the smooth operation of photovoltaic power supply system.

\section{The Calculation Of LoAd Resonance Frequency OF PHOTOVOLTAIC POWER SUPPLY}

\section{A. The algorithm for calculating the load resonance} frequency of photovoltaic power supply in the steady state

In order to reduce the complexity of the algorithm for calculating the load resonant frequency of the photovoltaic power supply in the steady state, this paper changes the topology structure of the converter in the photovoltaic power supply, transforms the components on the secondary side of the boosting transformer to the primary side, and places the components on the secondary side of the boosting transformer between the rectifier bridge and the resonant tank [6]. The simplified topology structure of the load resonance circuit of the photovoltaic power supply is shown in Fig. 1.

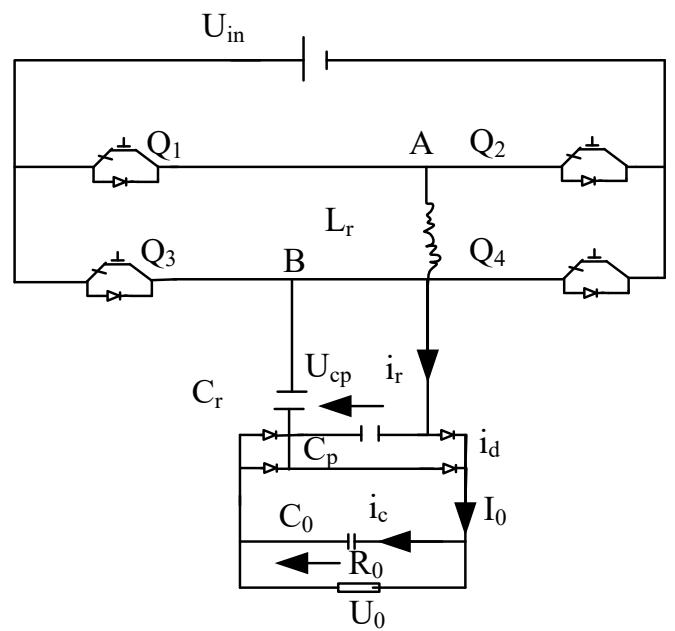

Fig. 1 the simplified topology structure of the load resonance circuit of the photovoltaic power supply

In Fig. 1, the $L_{r}$ is a series resonance inductance, the $C_{r}$ is a series resonance capacitance, the $C_{p}$ is a parallel resonance capacitance, the $C_{0}$ is a load capacitance transformed to the primary side of the transformer, and $R_{0}$ is a load resistance transformed to the primary side of the transformer. The $Q_{1}-Q_{4}$ represents inverters in different directions. In the load resonance circuit of photovoltaic power supply, when the resonance current in the circuit is continuous, the resonance frequency is less than the circuit switching frequency [7]. With this structure, the calculation model of resonant frequency of photovoltaic power supply load is constructed.

The mathematical model of the load resonance circuit of the photovoltaic power supply is based on the following assumptions: (1) The components used in the photovoltaic power supply circuit are ideal. (2) Within one switching cycle, the output voltage $U_{0}$ of the resonant circuit and the DC power supply voltage $U_{\text {in }}$ have clear values. According to Fig. 1 and the basic assumptions, in a switching cycle, the offset phase of the photovoltaic system is equal to the phase angle of the load, the time- domain equation of the resonant circuit can be obtained as follows:

$$
\left.\begin{array}{l}
L_{r} \frac{d i_{r}(t)}{d t}=-u_{e r}(t)-u_{e p}(t)+u_{A B}(t) \\
C_{r} \frac{d u_{e r}(t)}{d t}=i_{r}(t) \\
C_{0} \frac{d U_{0}(t)}{d t}=i_{d}(t)-\frac{U_{0}(t)}{R_{0}}
\end{array}\right\}
$$

Among them, $i_{r}(t)$ and $i_{d}(t)$ are the reference current of the inverter and the inductive current at one side of the inverter at the moment of $\mathrm{t}, u_{e r}$ is the output voltage of the capacitance, $u_{e p}$ is the output voltage of the inverter, and $u_{A B}$ is the voltage of the common connection. Consider that phase without offset, $\Delta \theta=0$.

Through the formula of the differential characteristic of the dynamic vector in (1), the forward offset phase is increased, the model of the dynamic phasor of the resonant circuit of the photovoltaic power supply is obtained:

$$
\left.\begin{array}{l}
L_{r} \frac{d\left\langle i_{r}\right\rangle_{1}}{d t}=-\left\langle u_{e r}\right\rangle_{1}-\left\langle u_{c p}\right\rangle_{1}+\left\langle u_{A B}\right\rangle_{1}-j L_{r} \lambda_{r}\left\langle i_{r}\right\rangle_{1} \\
C_{r} \frac{d\left\langle u_{e r}\right\rangle_{1}}{d t}=\left\langle i_{r}\right\rangle_{1}-j C_{r} \lambda_{r}\left\langle u_{e r}\right\rangle_{1} \\
C_{0} \frac{d\left\langle U_{0}\right\rangle_{0}}{d t}=\left\langle i_{d}\right\rangle_{0}-\frac{\left\langle U_{0}\right\rangle_{0}}{R_{0}}
\end{array}\right\}
$$

In the formula, $\lambda_{r}$ is a dynamic change threshold, subscript 1 is a component of a fundamental frequency, and subscript 0 is a component of a direct current. In order to reduce the tedious calculation, the duty cycle is set to a fixed value, and the switching power is set to a control variable, which enables the analysis of mathematical models [8] [9]. After adding positive/negative phase offset, the output power quality of photovoltaic power supply is almost unchanged. If the differential of the dynamic phasor in the differential equation in (2) is always equal to zero, the model for calculating the dynamic phasor of the resonant circuit of the photovoltaic power supply in the steady state is as follows: 


$$
\left.\begin{array}{l}
\left\langle i_{r}\right\rangle_{1 s s}=\left(\frac{H_{0}}{G_{0}}+J\right)\left(-\frac{2 U_{i n} G_{0}}{\left(G_{0}^{2}+H_{0}^{2}\right) \pi}\right) \\
\left\langle U_{c p}\right\rangle_{1 s s}=-\frac{2 U_{i n}}{\pi\left(G_{0}+j H_{0}\right) G_{r} \lambda_{s}} \\
\left\langle U_{0}\right\rangle_{0 s s}=-\frac{8 U_{i n} R_{0}}{\sqrt{G_{0}^{2}+H_{0}^{2}}\left(\pi^{2}+2 \pi C_{P} \lambda_{S} R_{0}\right)}
\end{array}\right\}
$$

In the formula, $U_{c p}$ is the current dynamic voltage value. In

$$
\begin{aligned}
& \text { the formula } H_{0}=L_{r} \lambda_{s}-\frac{1}{R_{r} \lambda_{s}}-\frac{\alpha_{s s}-0.5 \sin \left(2 \alpha_{s s}\right)}{\pi C_{p} \lambda_{s}}, \\
& G_{0}=\frac{\sin ^{2}\left(\alpha_{s s}\right)}{\lambda_{s} C_{p} \pi} \text { and } \alpha_{s s}=\cos ^{-1}\left(\frac{\pi-2 C_{p} R_{0} \lambda_{s}}{\pi+2 C_{p} R_{0} \lambda_{s}}\right) \text {, the subscript }
\end{aligned}
$$

ss indicates that the variable is a constant value. On this basis, considering that the frequency offset direction of disturbance signal is opposite to that of load resonance frequency, there will be interference to power quality. Therefore, the load resonance frequency of photovoltaic power supply in steady state is obtained by applying unidirectional frequency offset disturbance signal:

$$
w_{1}=\frac{64 U_{i n}^{2} R_{0}}{\left(\pi^{2}+2 \pi C_{p} R_{0} \lambda_{S}\right)^{2}\left(G_{0}^{2}+H_{0}^{2}\right)}
$$

Through the mathematical model of the load resonance circuit of the photovoltaic power supply, the load resonance frequency of the photovoltaic power supply in the steady state can be calculated [10]. Because photovoltaic power supply includes both steady and dynamic states, in order to calculate the load resonance frequency of the photovoltaic power supply in dynamic state, algorithms based on Wavelet Transform and Hilbert-Huang Transform need to be combined to calculate the load resonance frequency of photovoltaic power supplies in dynamic [11].

B. The algorithm for calculating the load resonance frequency of photovoltaic power supply in the dynamic state

The resonance detection based on wavelet transform and Hilbert-Huang transform. In this paper, $\mathrm{db}$ wavelet function is used to analyze the resonance signal of photovoltaic power supply, and db35 wavelet is used to decompose the resonance signal, which can reduce the distortion of the resonance signal of photovoltaic power supply to the minimum [12]. And the wavelet function has the characteristics of good computation and smooth in time-domain. The sampling frequency and vibration frequency of the signal determine the number of layers of wavelet decomposition [13]. The $f_{s}$ is defined as the sampling frequency and the $f_{0}$ is defined as the resonance natural frequency. The sampling theorem and wavelet analysis theory are used to decompose the resonance signal in the grid-connected photovoltaic power system. The variable can is defined as the low frequency signal in resonance signal, and the band range of candela is $0-\frac{f_{s}}{2^{n+1}}$. In order to reduce noise in the resonance frequency, the scale o needs to meet the following requirements:

$\frac{f_{s}}{2^{n+1}} \leq f_{0}$

The method of three-layer wavelet decomposition and frequency division of the Wavelet Transform used to analyze the resonance signal of the photovoltaic power system is shown in Fig. 2.

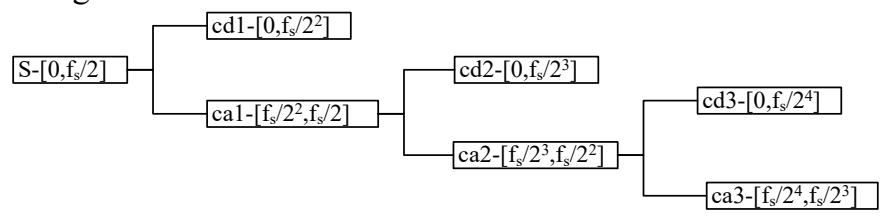

Fig. 2 three-layer decomposition of Wavelet Transform signals

From Fig. 2, it can be concluded that after the first layer of wavelet is used to decompose the original resonance signal $\mathrm{S}$ at the load end of the photovoltaic power supply, it is divided into the high-frequency signal cd 1 and the low-frequency signal ca1; After the second layer is used to decompose the low frequency signal ca1, the high-frequency signal cd 2 and the low-frequency signal ca2 are obtained. According to the law, the low-frequency signals are decomposed in turn, and the high-frequency signals are discarded. This process continues until the three-layer wavelet decomposition is completed [14] [15].

Harmonics are not the same as resonance. Periodic distortion is the distortion of grid-connected current and voltage caused by the influence of harmonics, which will gradually increase in amplitude with the number of cycles. The basic idea of Wavelet Transform and Hilbert-Huang Transform is to use Wavelet Transform to analyze the original signal at the load end of the photovoltaic power supply, extract the approximate signal from the harmonics, and then obtain the approximate signal through Hilbert- Huang Transform, which can improve the efficiency of calculation [16]. After the calculation, the results are obtained through the Hilbert-Huang Transform calculation. The analysis shows that the resonance signal is a signal whose amplitude gradually increases during the period of the harmonic signal. The detailed process of online resonance detection based on Wavelet Transform and Hilbert Huang Transform is described as follows:

(1) The synchronous sampling circuit is used to get the original resonance current or the original resonance voltage of the load end of the photovoltaic power supply in the grid-connected photovoltaic power supply system [17].

(2) The DSP platform is built to process the original signal. The original signal is analyzed by three-layer db35 wavelet analysis. The original signal is divided into two parts: low-frequency signal and high-frequency signal. Then the low-frequency signal is extracted. Among them, the transformed low-frequency signal includes a relatively comprehensive approximate signal in harmonics.

(3) The Hilbert-Huang Transform is used to analyze Wavelet Transform and extract approximate signals in harmonics, which 
is used to draw time-frequency curves and time-amplitude curves [18]. The two curves indicate the trends of the frequency and amplitude of the fundamental and harmonic components.

(4) After Hilbert-Huang Transformation, it can be concluded that the amplitude of some harmonics gradually increases with the increase of the period. The frequency near this harmonic frequency is the resonance frequency. Wavelet Transform and Hilbert-Huang Transform algorithm can be used to detect whether there is a resonance signal in the photovoltaic power supply load of the grid-connected photovoltaic power system in a dynamic environment. If the resonance signal exists in the load of the photovoltaic power supply, we need to analyze and calculate the load resonance frequency of the photovoltaic power supply in the grid-connected photovoltaic power supply system.

The analysis and calculation of the load resonance frequency of photovoltaic power supply. The structure of grid-connected photovoltaic power system is composed of inverter, filter device, power grid and photovoltaic array. The structure of grid-connected photovoltaic power system is shown in Fig. 3.
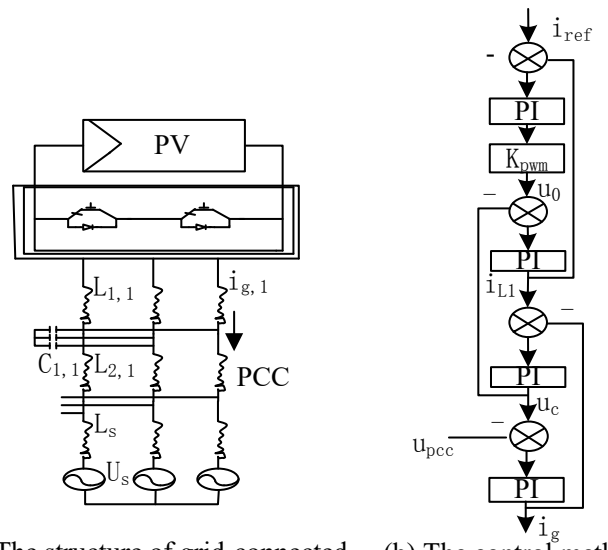

$\begin{array}{lll}\text { (a) The structure of grid-connected } & \text { (b) The control method of grid- }\end{array}$ photovoltaic power system connected photovoltaic power system

Fig. 3 the whole structure of grid-connected photovoltaic power system

In Fig. 3(a), the $U_{s}$ is the voltage of the power grid, the $L_{s}$ is the grid inductance, the $L_{1}$ is the inverter, $\mathrm{C}$ is the capacitance in the filter, the $L_{2}$ is the inductance on the grid side, and the $i_{g}$ is the current on the grid side of the inverter. The PCC is the common connection. The grid-connected photovoltaic power system controls the current and voltage through the inverter. As shown in Fig. 3(b), the PI is the controller that controls the current, the $k_{p w m}$ is the equivalent proportional coefficient of the inverter bridge, the $i_{r e f}$ and $i_{L 1}$ are the reference current of the inverter and the current of the inductance on the inverter side, the $u_{c}$ and $u_{0}$ are the output voltages of the capacitance and the inverter, and the $u_{p c c}$ is the voltage of the PCC. According to Fig. 3 , the schematic diagram of the resonance of the photovoltaic power supply system is obtained, as shown in Fig. 4. The $i_{L 2}$ is the current of the inductance on the grid side, and the $\mathrm{n}$ is the number of parallel devices of the inverters in the photovoltaic power supply.

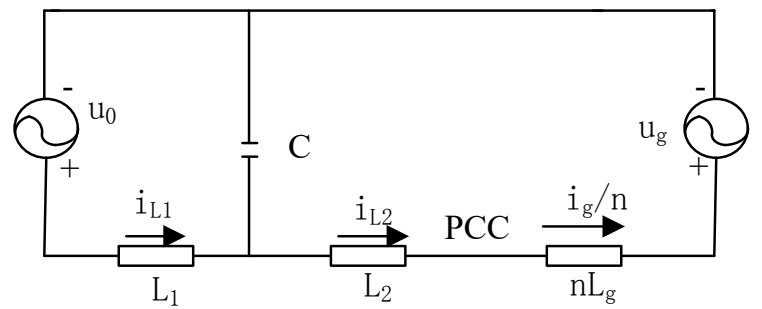

Fig. 4 schematic diagram of resonance

The calculation of load resonance frequency of photovoltaic power supply in dynamic state is based on Fig. 4, and the calculation result is as follows:

$w_{2}=\sqrt{\frac{1}{L_{1} C}}\left(1+\frac{L_{1}}{L_{2}+n L_{g}}\right)$

From (6), it can be concluded that under dynamic conditions, the load resonance frequency of the photovoltaic power supply is related to the number and parameters of the parallel inverters in the photovoltaic power supply.

\section{EXPERIMENTAL ANALYSIS}

MATLAB is used to build a simulation platform for grid-connected photovoltaic power. The paper simulates 10 photovoltaic power supplies, and sets the parameters of the grid-connected photovoltaic power system as follows: The setting of the bridge arm inductance is between $3 \mathrm{mH}$ and $4 \mathrm{mH}$, the value of the inductance is between $0.57 \mathrm{mH}$ and $0.71 \mathrm{mH}$, and the sampling frequency is between $10.24 \mathrm{kHz}$ and $12.8 \mathrm{kHz}$.

A. The detection of voltage resonance waveform of photovoltaic power system

The method in this paper is used to detect the resonance in the photovoltaic power supply in the simulation. It detects the waveform of the resonance voltage at the load end of the photovoltaic power supply to determine whether there is resonance in the photovoltaic power supply. The result is shown in Fig. 5.

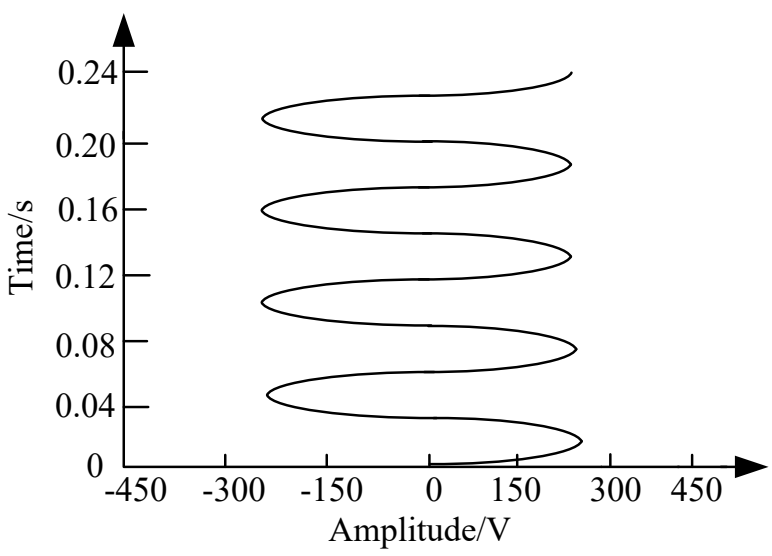

Fig. 5 waveform of the load resonance voltage of photovoltaic power supply

According to Fig. 5, it can be concluded that the amplitude of the load voltage of the grid-connected photovoltaic power supply periodically changes with time, and the highest and 
lowest values are $-200 \mathrm{~V}$ and $200 \mathrm{~V}$, which indicates that there is resonance at the load end of the grid-connected photovoltaic power.

B. The relationship between the load resonance frequency and efficiency of photovoltaic power supply

When calculating the load resonance frequency of a photovoltaic power supply, it is needed to analyze the relationship between the resonance frequency and the operation efficiency of the power supply. We consider the relationship between the resonant frequency of the load of the photovoltaic power supply and the operation efficiency of the photovoltaic power supply under two different assumptions. The first is the relationship between the operation efficiency of photovoltaic power supply and the load resonant frequency of photovoltaic power supply when there is a difference between the load resonant frequency of photovoltaic power supply and the resonant frequency of wireless power transmission, as shown in Fig. 6. The second case is the relationship between the operation efficiency of the photovoltaic power supply and the load resonant frequency of the photovoltaic power supply when there is not a difference between the load resonant frequency of photovoltaic power supply and the resonant frequency of wireless power transmission, as shown in Fig. 7.

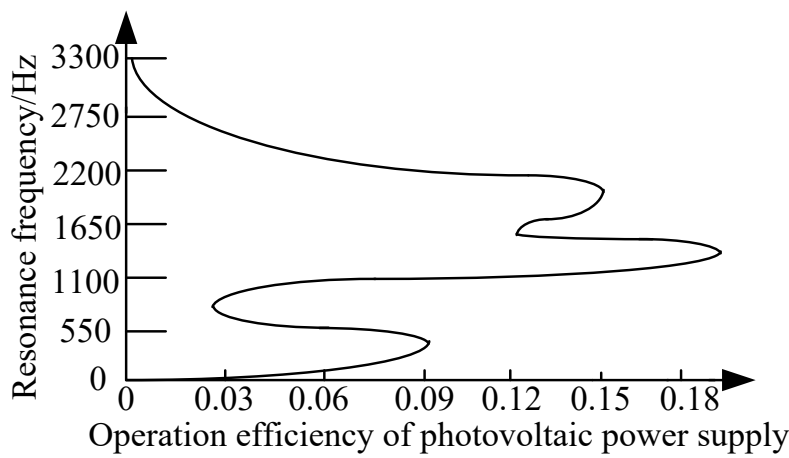

Fig. 6 The operation efficiency of photovoltaic power supply at different resonance frequencies

From Fig. 6, it can be seen that when the resonance frequency values are $315.6 \mathrm{~Hz}, 1398.4 \mathrm{~Hz}$, and $1932.8 \mathrm{~Hz}$, the operation efficiency of the photovoltaic power supply reaches the maximum value. When the resonance frequency value is 1398.4 $\mathrm{Hz}$, the operation efficiency of the photovoltaic power supply reaches the maximum value, and the maximum operation efficiency of the photovoltaic power supply is 0.182 .

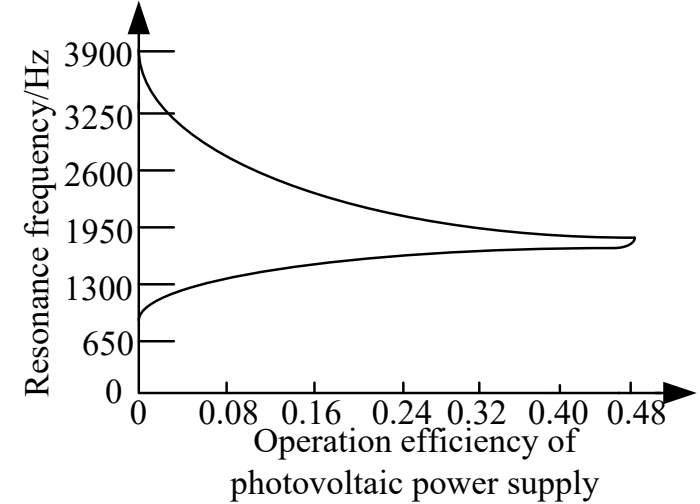

Fig. 7 the operation efficiency of photovoltaic power supply at the same resonance frequency

As shown in Fig. 7, when the resonance frequency is 1879.6 $\mathrm{Hz}$, the operation efficiency of the photovoltaic power source is the largest, and the maximum value is 0.481 . By comparing Fig. 6 and Fig. 7, it can be concluded that when the load resonance frequency of the photovoltaic power source is consistent with the resonance frequency of the wireless transmission of electrical energy, the operation efficiency of the photovoltaic power source is higher. In summary, when the algorithm of the paper is used to calculate the resonant frequency of the load of the photovoltaic power supply, it is necessary to ensure that the calculated resonant frequency of the load of the photovoltaic power supply is consistent with the resonance frequency of the wireless transmission of electrical energy to ensure that the operation efficiency of the photovoltaic power supply is at its maximum.

\section{The detection of the effect of resonance signals}

In the paper, the above-mentioned algorithm is used to detect the resonance voltage signal and field resonance signal of the grid-connected photovoltaic power system online. The detection results are shown in Fig. 8 and Fig. 9.

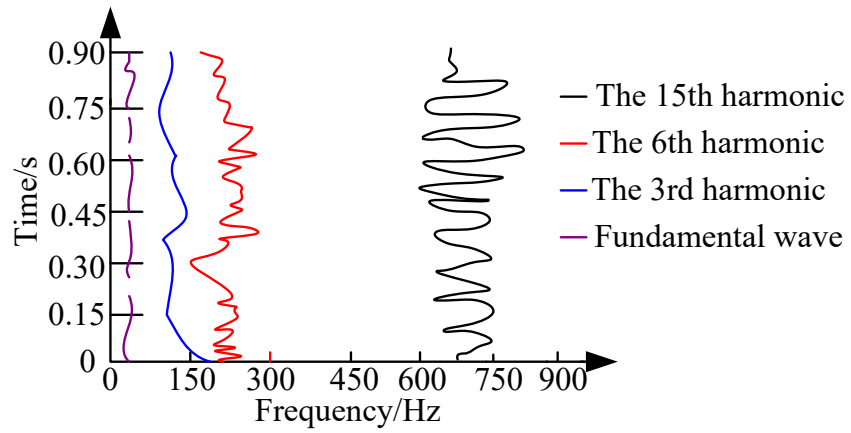

Fig. 8 detection of resonance voltage signal of photovoltaic power system

Fig. 8 shows that the amplitude of the 6th harmonic is gradually increasing, while the amplitude of the 15th harmonic is gradually increasing, and the amplitude of the 3rd harmonic is relatively small. According to the amplitude of harmonics, the gradual increase indicates that there are harmonics in the photovoltaic grid-connected power generation system. Therefore, it can be concluded that the harmonic frequencies of the grid-connected photovoltaic power system are $251.68 \mathrm{~Hz}$ 
and $706.15 \mathrm{~Hz}$.

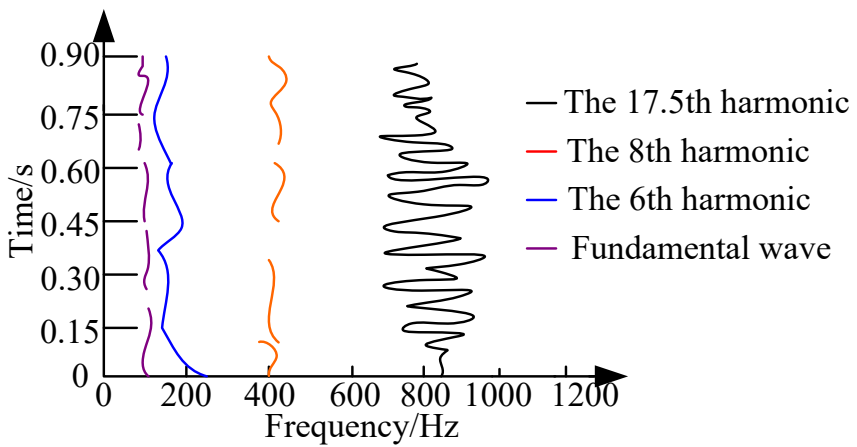

Fig. 9 detection of field resonance signal of photovoltaic power system

Fig. 9 shows that the amplitude of the 7 th harmonic is gradually increasing, while the amplitude of the 17.5 th harmonic is gradually increasing, and the amplitude of the 6th

Table I Comparison between the actual value and calculated value of the resonance of photovoltaic power supply

\begin{tabular}{|c|c|c|c|c|}
\hline Method & NO. of photovoltaic power supply & Calculated value & Actual value & Error \\
\hline \multirow{8}{*}{ The method proposed in this paper } & 1 & 17.91 & 17.89 & $0.11 \%$ \\
\hline & 2 & 13.87 & 13.84 & $0.22 \%$ \\
\hline & 3 & 10.16 & 10.11 & $0.49 \%$ \\
\hline & 4 & 12.95 & 12.56 & $3.11 \%$ \\
\hline & 5 & 19.81 & 19.87 & $-0.30 \%$ \\
\hline & 6 & 21.37 & 21.29 & $0.38 \%$ \\
\hline & 9 & 29.16 & 29.09 & $0.24 \%$ \\
\hline & 10 & 30.51 & 30.46 & $0.16 \%$ \\
\hline \multirow{7}{*}{ The method based on neural network } & 1 & 16.45 & 17.89 & $-8.05 \%$ \\
\hline & 2 & 15.89 & 13.84 & $14.81 \%$ \\
\hline & 3 & 8.72 & 10.11 & $-13.75 \%$ \\
\hline & 7 & 22.16 & 25.79 & $-14.08 \%$ \\
\hline & 8 & 31.68 & 27.61 & $14.74 \%$ \\
\hline & 9 & 24.69 & 29.09 & $-15.13 \%$ \\
\hline & 10 & 25.31 & 30.46 & $-16.91 \%$ \\
\hline
\end{tabular}

From Table I, it can be seen that the load resonance frequency of the photovoltaic power supply calculated by the method proposed in this paper is slightly different from the actual load resonance frequency value of the photovoltaic power supply, and the error range is between $-0.30 \%$ and $0.49 \%$. The load resonance frequency calculated by the method based on neural network is significantly different from the actual load resonance frequency value of the photovoltaic power supply, and the error range is between $-8.05 \%$ and $20.76 \%$. That is to say, the accuracy of the load resonance frequency value of the photovoltaic power supply calculated by the method proposed in this paper is higher, which is more suitable for the independent calculation of the actual load resonant frequency of photovoltaic power supply.

To sum up, it can be known that when the load resonant frequency of photovoltaic power supply is consistent with the resonant frequency of wireless power transmission, the harmonic is relatively small. Therefore, it can be concluded that the harmonic frequencies of the grid-connected photovoltaic power system are $251.68 \mathrm{~Hz}$ and $706.15 \mathrm{~Hz}$.

\section{The analysis of errors in calculation}

In order to verify the accuracy of the method proposed in this paper for calculating the load resonance frequency of the photovoltaic power supply, different photovoltaic power supplies will be used for experiments, and the calculation value of the load resonance frequency of photovoltaic power supply obtained by the method proposed in this paper and the method based on neural network will be compared, and the calculation error will be analyzed. The results are shown in Table I. operation efficiency of photovoltaic power supply is higher. Therefore, it should be ensured that the resonant frequency of the load of photovoltaic power supply is consistent with the resonant frequency of wireless power transmission, so as to ensure that the operation efficiency of photovoltaic power supply reaches the maximum. According to the detected harmonic amplitude, when it gradually increases, it indicates that there are harmonics in the photovoltaic grid-connected power generation system, and the harmonic frequency is the resonance frequency. The error of load resonance frequency calculated by the method presented in this paper is between $-0.30 \%$ and $0.49 \%$. And has superior performance.

\section{CONCLUSION}

This paper proposes an automatic calculation method for the load resonant frequency of the photovoltaic power supply. By simplifying the topology structure of the load resonant circuit of 
the photovoltaic power supply, the time-domain equation of the resonant circuit is obtained. According to the time-domain equation, the dynamic phasor model of the resonant circuit of the photovoltaic power supply in the steady state is calculated to obtain the load resonant frequency of photovoltaic power supply in the steady state. The sampling theorem and wavelet analysis theory are used to decompose the resonance signal in the grid-connected photovoltaic power system, and a relatively comprehensive approximate signal in the harmonic component is extracted. The Hilbert-Huang Transform is used to analyze the approximate signal to detect whether there is a resonance signal at the load end of the photovoltaic power supply in the grid-connected photovoltaic power system. If the detection result shows that there is a resonance signal at the load end of the photovoltaic power supply, it is necessary to analyze and calculate it. According to the calculation results of the load resonance frequency of the photovoltaic power supply in the dynamic state, it is found that the load resonance frequency of the photovoltaic power supply in dynamic condition is related to the number and parameters of parallel inverters in photovoltaic power supply.

By testing the performance of the proposed method, it can be found that the operating efficiency of photovoltaic power supply can be maximized when the load resonance frequency of photovoltaic power supply is consistent with the frequency of power transmission. According to the state of harmonic amplitude, when it gradually increases, it indicates that the harmonic frequency is the load resonance frequency. Moreover, the load resonance frequency error calculated by this method is smaller, ranging from $-0.30 \%$ to $0.49 \%$, which is more accurate than other methods. The method proposed in this paper can quickly and accurately obtain the load resonance frequency of photovoltaic power supply. By calculating the load resonance frequency of photovoltaic power supply, the photovoltaic power supply can be repaired and adjusted in time to ensure the normal operation of photovoltaic power supply system. However, the method proposed in this paper has not been applied in practice, and the actual environmental impact has not been fully considered. In the future research, it is necessary to apply the proposed method to the actual photovoltaic power supply system and continuously improve it to improve its applicability.

\section{References}

[1] X. K. Fang and Y. Y. An, "Study on maximum power point tracking method and experiment of photovoltaic power based on sudden changing load," Electrical Measurement \& Instrumentation, vol. 54, no. 3, pp. 19-24, 2017.

[2] O. Ourahmoun, "Electrical parameters of organic photovoltaic cells under QUCS and GPVDM software," WSEAS Transactions on Circuits and Systems, vol. 19, pp. 196-205, 2020.

[3] N. Neeraj, P. Pravesh, and S. Pal, "Fundamental materialistic properties of $\mathrm{ZnSnP2}$ for solar energy conversion and environmental friendly photovoltaic devices," WSEAS Transactions on Circuits and Systems, vol. 19, pp. 43-61, 2020.
[4] F. Khosrojerdi, S. Gagnon, and R. Valverde, "Proposing a knowledge-based model for photovoltaic modules operating under shading conditions," WSEAS Transactions on Computers, vol. 19, pp. 224-233, 2020.

[5] L. X. Zhou, D. Zhang, and C. B. Li, "Access capacity analysis considering correlation of distributed photovoltaic power and load," Automation of Electric Power Systems, vol. 41, no. 4, pp. 56-61, 2017.

[6] S. Oncu and S. Nacar, "Soft switching maximum power point tracker with resonant switch in PV system," International Journal of Hydrogen Energy, vol. 41, no. 29, pp. 12477-12484, 2017.

[7] K. Dang and M. T. Wang, "Online load frequency technique of photovoltaic micro-grid," Computer Simulation, vol. 34, no. 11, pp. 53-57, 2017.

[8] J. S. Zhou, R. X. Gong, and W.F. Tan, "Research on battery charging strategy in independent photovoltaic system," Chinese Journal of Power Sources, vol. 39, no. 11, pp. 2429-2432, 2015.

[9] W. Zhu and Y.J. Liu, "Research on harmonic resonance mechanism of large-scale photovoltaic power stations," China Electric Power, vol. 51, no. 3, pp. 121-130, 2018.

[10] S. Omata and T. Shimizu, "Design method for EMI filters connected to both $\mathrm{dc}$ and ac ports of a residential-use photovoltaic power conditioner," Electrical Engineering in Japan, vol. 197, no. 2, pp. 56-67, 2016.

[11]Y. Zhao, Z. L. Yang, and D. F. Cao, "Analysis and mitigation of pvpccpointharmonics in weak grid," Acta Energiae Solaris Sinica, vol. 39, no. 1, pp. 117-123, 2018.

[12] C. Zheng, L. Zhou, and M. Zhang, "Harmonic resonance suppression based on admittance reshaping for large-scale pvplant," Electric Power Automation Equipment, vol. 36, no. 8, pp. 51-57, 2016.

[13] M. Mirhosseini, J. Pou, and B. Karanayil, "Resonant versus conventional controllers in grid-connected photovoltaic power plants under unbalanced grid voltages," IEEE Transactions on Sustainable Energy, vol. 7, no. 3, pp. 1124-1132, 2016.

[14] S. P. Liu, F. Z. Luo, and C. S. Wang, "Calculation method of hosting capacity for distributed grid-connected photovoltaic based on improved big bang-big crunch algorithm," Proceedings of the CSU-EPSA, vol. 29, no. 11, pp. 1-6, 2017.

[15]F. Zhang, B. B. Yue, and Y. K. Zhang, "Research on maximum power point tracking for solar power system," Chinese Journal of Power Sources, vol. 39, no. 11, pp. 2549-2551, 2015.

[16]Z. Y. Ren, W. Yan, and B. Xiang, "Probabilistic power flow analysis incorporating the correlations between PV power outputs and loads," Transactions of China Electrotechnical Society, vol. 30, no. 24, pp. 181-187, 2015.

[17] J. Gao, P. Li, and J. Sun, "Analysis of resonance distribution range and influence factors of clustered distributed photovoltaic," Advances of Power System \& Hydroelectric Engineering, vol. 32, no. 7, pp. 125-131, 2016. 
[18] X. D. Luo and J. B. Cui, "Parameter optimization design for LCL filter of photovoltaic grid-connected inverter," Journal of Shenyang University of Technology, vol. 38, no. 6, pp. 601-605, 2016.

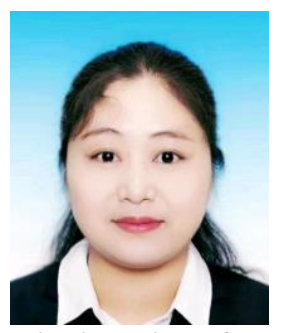

Xinying Zhao, female, was born in September, 1978. Her title is Associate Professor. She graduated from Central South University in 2002, major in Communication, with a Bachelor Degree. She graduated from Huazhong University of Science and Technology in 2007, major in Communication and Information System, with a Master Degree of Engineering. Now she is working in Department of Electronic Engineering, Zhengzhou Railway Vocational and Technical College. She mainly engages in the research of Electronic information and Communication. So far, she has published 15 academic articles, participated in 8 scientific research projects and more than 15 other academic achievement.

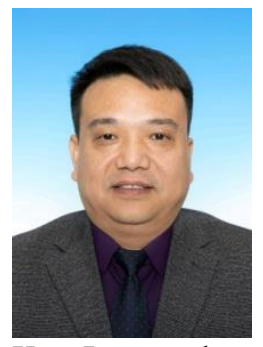

Kun Luo, male, was born in August, 1978. His title is Senior Experimentalist. He graduated from Zhengzhou University in 2004, major in Electronic and Information Engineering, with a Bachelor Degree. He graduated from Huazhong University of Science and Technology in 2009, Major in Communication and information System, with a Master Degree of Engineering.

Now he is working in School of International Education, Zhengzhou Railway Vocational and Technical College. He mainly engages in the research of Electronic information and Communication. So far, He has published 8 academic articles, participated in 3 scientific research projects.

\section{Author Contributions:}

Xinying Zhao, the resonance detection algorithm based on wavelet transform and Hilbert-Huang transform is used to analyze and calculate the load resonance frequency after detecting the resonance signal of photovoltaic power system. Kun Luo Experiments were done. All authors discussed the results and wrote the manuscript.

\section{Creative Commons Attribution License 4.0 (Attribution 4.0 International, CC BY 4.0)}

This article is published under the terms of the Creative Commons Attribution License 4.0

https://creativecommons.org/licenses/by/4.0/deed.en_US 